pandemic played important roles in the mortality burden. The datasets based on archival sources provide a rich foundation for both historical and epidemiological research of the mortality burden among these military personnel during World War I.

\section{SP6-42 PHYSICAL ACTIVITY IS ASSOCIATED WITH REDUCED MORTALITY IN A RURAL SOUTH INDIAN COHORT}

doi:10.1136/jech.2011.142976q.13

\begin{abstract}
1,2V Raman Kutty, ${ }^{*} \mathrm{~S}$ Safraj, ${ }^{2,3} \mathrm{~K}$ Vijayakumar, ${ }^{3} \mathrm{~T} \mathrm{~S}$ Anish, ${ }^{2} \mathrm{~K}$ Ajayan. ${ }^{1}$ Achutha Menon Centre, SCTIMST, Trivandrum, Kerala state, India; ${ }^{2}$ Health Action by People, Trivandrum, Kerala state, India; ${ }^{3}$ Department of Community Medicine, Medical College, Trivandrum, Trivandrum, Kerala state, India
\end{abstract}

Introduction Physical activity is now recognised as an important determinant of health status. Thus it is important to explore its relation to mortality in transitional populations.

Methods We examined the association between self reported physical activity and mortality in a rural adult cohort numbering over 70000 in southern India in the first 5 years of observation, from 2001 to 2006. The scores assigned under occupational and nonoccupational recreational categories based on previous studies, were added to arrive at a total activity score. Based on this, we categorised subjects into those with mild, moderate, and heavy physical activity.

Results There is an inverse relationship between death rate and physical activity, with a much greater effect in women, true for both all cause and cardiovascular mortality. The effect is more pronounced in smoking males compared to non-smoking males. The protection offered by physical activity is also more evident in subjects aged $40-65$ years. Heavy physical activity does not seem to confer proportionately greater protection as compared to moderate activity.

Conclusion Our observations confirm published reports on the protective effect of physical activity on health. Our data support the possibility that subjects with poor physical activity have more chronic morbidity, which underlies higher mortality. Clear cut relationships would emerge only with longer term follow-up of the cohort with physical activity profiles being captured at regular intervals.

\section{SP6-43 ETHNIC GRADIENT IN MORTALITY AMONG THE NEW ZEALAND MILITARY PERSONNEL IN WORLD WAR I}

doi:10.1136/jech.2011.142976q.14

J A Summers, ${ }^{*}$ N Wilson, M G Baker. University of Otago, Wellington, New Zealand

Introduction The ethnic distribution in mortality rates for New Zealand (NZ) military personnel in World War I has never been described.

Methods Mortality data for military personnel in the NZ Expeditionary Forces (NZEF) were obtained from an electronic dataset (Roll-of-Honour) covering all deaths in these personnel during World War I and the immediate post-war period (1914-1923). All NZEF were allocated (using a classification system based on names and background) into the following ethnic groups: European/Other, Māori (indigenous New Zealanders) and Pacific peoples.

Results The highest all-cause mortality (deaths from enemy action, wounds, disease, and other) was experienced by Māori personnel. The majority of deaths among European/Other and Māori personnel were a result of being killed in action. Pacific personnel experienced the lowest all-cause mortality rate. Mortality rates from disease varied greatly by ethnic group, with Māori and Pacific personnel both experiencing higher rates than European/Other personnel.
When deaths from the 1918 to 1919 influenza pandemic are excluded from the analysis, Māori and Pacific personnel still had significantly higher mortality rates from disease compared to European/Other personnel (rate ratio 3.92, 95\% CI 3.14 to 4.91 and rate ratio $3.45,95 \%$ CI 2.42 to 4.91 ).

Conclusions We document for the first time higher all-cause mortality burden among Māori compared with European/Other for NZ's World War I effort. Also identified was the large variation in disease mortality, with Māori and Pacific personnel suffering to a disproportionately greater extent. These historical results serve as a reminder that tackling health inequalities is a long-term commitment that requires ongoing public health attention.

\section{SP6-44 "AN APPROPRIATE APPROACH FOR RCH SERVICES DELIVERY THROUGH INCENTIVE BASED FEMALE ACTIVIST (ASHA) FOR RURAL AREA IN KANPUR DISTRICT, UTTAR PRADESH, INDIA"}

doi:10.1136/jech.2011.142976q.15

S C Saxena, * A Singh, V K Srivastava, D S Martolia, P Varma, R P Sharma. GSVM Medical College, Kanpur University, Kanpur, Uttar Pradesh, India

Introduction In India, in the year 2005, the concept of Accredited Social Health Activist (ASHA)-incentive based female volunteer was implemented under NRHM with an objective that these female volunteers in co-operation with already existing other healthcare functionaries will facilitate the proper implementation of $\mathrm{MCH}$ programmes having an impact in the reduction of infant mortality rate and maternal mortality rate.

Methodology All the 135 female health volunteers of randomly selected primary health centres of Kanpur were studied by predesigned and pretested questionnaire.

Results Predominantly the selected female health volunteers belonged to age group of $30-35$ years $(45.2 \%)$, Hindu by religion (99.3\%), OBC caste (54.1\%), educated upto middle standard $(57.8 \%)$ and from Social Class IV (68.9\%). About 2/3rd these volunteers had received the required two rounds of training but anyhow the remaining were partially trained. All the female health volunteers performed $100 \%$ activities regarding antenatal, intranatal and postnatal care and to lesser extent on adolescent's education about RTIs/STIs as well as supplementary nutrition. For improving their performance, all the health volunteers suggested about making their jobs permanent with fixed salary. Nearly half to $3 / 4$ th of them were in favour of providing transport as well as well as adequate training and mobile phone facility.

\section{SP6-45 SCREENING FOR GENITAL CHLAMYDIA FOR YOUNG PEOPLE IN COMMUNITY PHARMACIES: A META-ANALYSIS OF CHLAMYDIA PREVALENCE}

doi:10.1136/jech.2011.142976q.16

M Z Kapadia,* P Warner, K Fairhurst. Centre for population Health sciences, University of Edinburgh, Edinburgh, Scotland, UK

Background With traditional specialist sexual-health services overstretched, community pharmacies have been deployed to provide chlamydia testing. We have undertaken a systematic-review to estimate prevalence of chlamydia infection among those screened for chlamydia in community pharmacies. We also reviewed the feasibility/acceptability of this service.

Methods Systematic searches were conducted in electronic databases and grey literature was solicited from experts. Data were extracted on study population, sample size and prevalence of chlamydia to report pooled proportion of chlamydia infection using random effect model. 